\title{
HEPATITIS FULMINANTE EN LA SIERRA NEVADA: UNA FORMA DE SUPERINFECCION DEL VIRUS DELTA CON EL VIRUS DE LA HEPATITIS B.
}

\begin{abstract}
Alvaro Villanueva*, Patricia A. Fraser**, Rafael García**, Pedro Ospino**, Pedro Ariza**, Thomas O' Brien ${ }^{\star \star \star}$.

Durante septiembre de 1980 a octubre de 1983, se realizó un estudio seroepidemiológico para hepatitis A y B, en 258 personas en una ciudad (Santa Marta) población de 250.000 y tres pequeños municipios (Santa Rosalía, Julio Zawady y Aracataca), poblaciones de 768,800 y 5.000 habitantes respectivamente. La presencia de hepatitis A se encontró en un 77 a $93 \%$ (IgG Hepatitis A). Hbs Ag o Anti-Hbs Ag en $30.5 \%$ de la población en dos municipios (Santa Rosalía y Julio Zawady), en $2.5 \%$ en el municipio de Aracataca y $48.5 \%$ en la ciudad de Santa Marta. La presencia del Agente Delta (Anti-delta en el suero) se determinó también en estas mismas poblaciones, encontrándose ausente en la ciudad y uno de los municipios (Aracataca), en contraste con una prevalencia de $13.7 \%$ y $22 \%$ en Julio Zawady y Santa Rosalía (P: 0.0001). Se excluyeron por historia clínica, antecedentes de drogadicción, transfusiones, o prácticas homosexuales, como mecanismos de transmisión de los virus B y delta.
\end{abstract}

En veinte pacientes con diagnóstico histopalógico de hepatitis fulminante y en quienes se descartaron otras etiologías se demostró la presencia serológica de los virus de la hepatitis By Delta. De estos veinte, diez provenían de Julio Zawady y los otros diez de Santa Rosalía. La evolución clínica de esta enfermedad fue indistinguible de otras causas de falla hepática aguda. La mortalidad de estas formas fulminantes de hepatitis alcanzaron hasta un $65 \%$. Los corticoides no modificaron el curso de esta enfermedad. La población joven mostró mayor compromiso y peor diagnóstico (P:0.033). La hepatitis fulminante de la Sierra Nevada de Santa Marta es el resultado de la superinfección con el virus Delta sobre la infección virus B. La aparición simultánea de casos intrafamiliares sugiere una relación importante entre los grupos comprometidos, aunque la forma exacta de transmisión permanece aún desconocida.

\section{INTRODUCCION}

El virus Delta ha sido caracterizado como una partícula de 35 a $37 \mathrm{~nm}$ de tamaño, constituído por RNA ( peso molecular: $500 \mathrm{kd} \mathrm{y}$ una proteína interna (el antígeno delta) cubierta con el antígeno de superficie (Hbs-Ag). (1).
La infección puede ocurrir como una coinfección la cual usualmente se resuelve de manera favorable, pero en pocas ocasiones puede ocasionar cuadros severos, mientras que la superinfección frecuentemente produce la forma fulminante. (2). Los estudios serológicos, indican que la hepatitis por virus Delta tiene

* Hospital San Juan de Dios Departamentos de Medicina y Patologia

** Servisalud -Magdalena, Santa Marta

$\star \star \star$ Brigham and Women's Hospital Departamentos de Medicina y Bioestadísticas Harvard School of Public Health, Boston Massachuttes 
una amplia distribución universal (3). En el Norte de Colombia, una forma fulminante de hepatitis ha sido descrita desde hace 50 años (4), localizada en un área geográfica, la Sierra Nevada de Santa Marta (Figura 1), donde existe una alta prevalencia de la hepatitis Delta asociada con el virus de la hepatitis B. En este artículo describiremos la evolución clínica, serológica e histológica de 20 pacientes con hepatitis fulminante de la Sierra Nevada de Santa Marta.

\section{MATERIALES Y METODOS}

\section{Descripción del Area}

La Sierra Nevada de Santa Marta es una región montañosa del norte de Colombia rodeada por los departamentos del Cesar y Magdalena, y cercana al Océano Atlántico. Constituye un macizo rocoso cubierto por nieve, con una altura máxima aproximada de 6.000 metros (5). El área es predominantemente un bosque

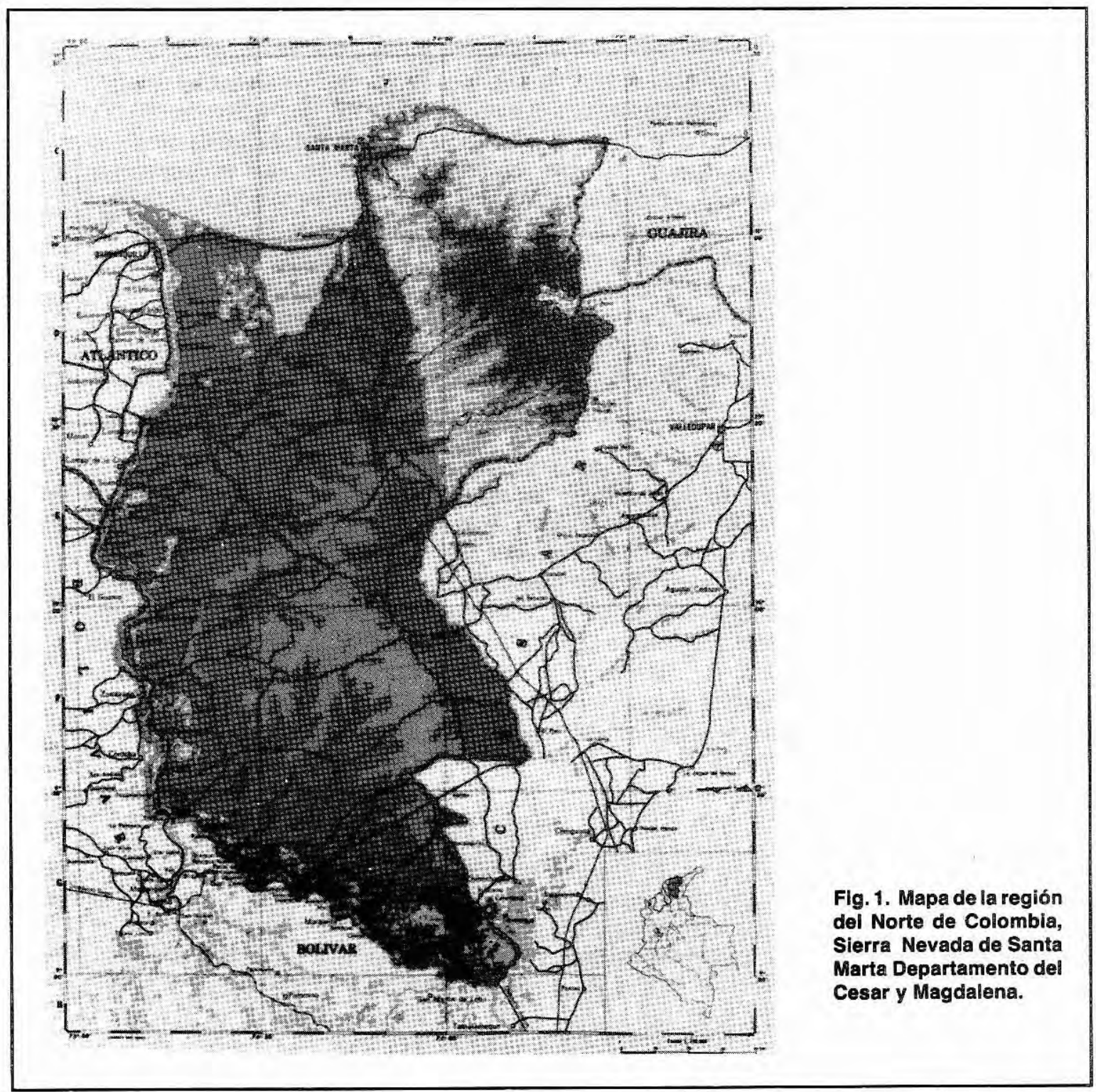


trópical, localizada a $150 \mathrm{~km}$. aproximadamente de la ciudad de Santa Marta, capital del departamento del Magdalena, con una población aproximada de 500.000 habitantes. Las poblaciones de Aracataca, Santa Rosalía, Julio Zawady, tienen aproximadamente $5.000,768$ y 800 habitantes, respectivamente.

\section{Población}

En septiembre de 1980 y octubre de 1983 se estudiaron cuatro poblaciones: La ciudad de Santa Marta y los Municipios de Aracataca, Julio Zawady y Santa Rosalía. En la primera de las muestras fueron obtenidas de donantes del Banco de Sangre del Hospital San Juan de Dios. En los 3 muncipios anotados se tomaron muestras al azar en voluntarios, a un total de 258 personas, practicándoseles marcadores para hepatitis A, B y Delta (Gráfica No. 1).

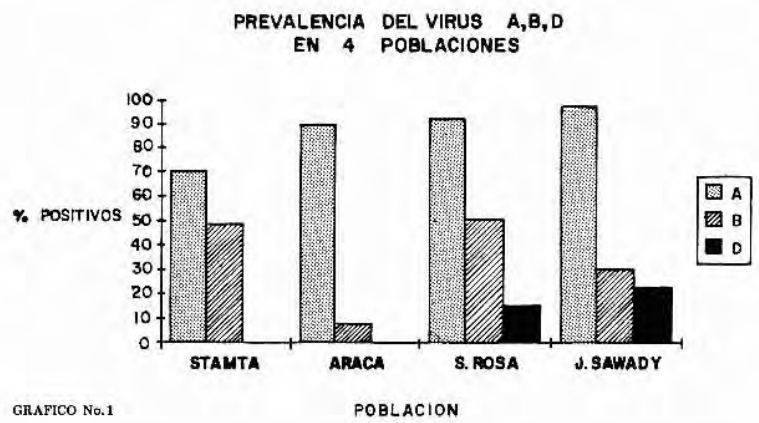

Todos los pacientes con el diagnóstico posible de hepatitis fueron ubicados en el Hospital San Juan de Dios en Santa Marta; éstos eran referidos de las poblaciones vecinas, constituyendo un grupo poblacional de mestizos. La mayoría de los pacientes tenían un estrato socio-económico bajo y su forma de sustento dependía principalmente de la agricultura. Todos los pacientes con estudios histopatológicos provenían de los municipios de Julio Zawady y Santa Rosalía.

\section{Selección de pacientes y seguimiento}

Fueron estudiados todos los pacientes que se presentaron al Hospital San Juan de Dios con un síndrome ictérico agudo no quirúrgico. La historia clínica y el examen físico se registra- ron en un formato previamente diseñado para el estudio de hepatitis, el cual contenía la historia del paciente, datos epidemiológicos, y exámenes de laboratorio, incluyéndose además de los de rutina, estudios de función hepática y pruebas de coagulación. Unos $20 \mathrm{ml}$ de suero eran obtenidos de cada paciente y se congelaban a $70^{\circ} \mathrm{C}$ para posterior análisis. Los pacientes que sobrevivieron de la enfermedad aguda fueron seguidos durante tres ( 3 ) meses después de la hospitalización.

\section{Criterios para hepatitis fulminante}

Los criterios para hepatitis fulminante fueron:

1. Manifestaciones clínicas de una falla hepática severa

2. Seropositividad para ambos Hbs-Ag, antiHD (anticuerpos para Delta IgM) y seronegatividad para anticuerpos contra el antígeno central (anti-HBcAg, IgM).

3. Hallazgos histopatológicos de la Hepatitis de Santa Marta (6).

4. Exclusión de otras causas de síndrome ictérico agudo.

\section{Estudios serológicos}

Estudios inmunoenzimáticos (EIA, Abott Labs, Chicago, Ill), fueron utilizados para determinar $\mathrm{HD} \mathrm{Ag}$, Hbs, anti $\mathrm{HBC} \mathrm{Ag}$ y anticuerpos de HBs Ag.

\section{Biopsias hepáticas}

Las muestras hepáticas fueron obtenidas por biopsia percutánea, viscerotomía o autopsia de los pacientes fallecidos y fijadas por los métodos de estudio hispotatológico de rutina. Dos de las muestras fueron estudiadas para Antígeno Delta por el método de inmunoperoxidasa (7).

\section{Análisis estadístico}

El análisis se hizo por la prueba de Chi cuadrado (X2) y se tabuló en un computador Macintosh Plus utilizando el programa estadístico de la Statview, 512 (Brainpower, Inc, 
Calabasas, Ca). Pruebas de exactitud de Fischer fueron practicadas en el Tops-20 Computer, del Dana Farber Cancer Institute, utilizando el Fexact Program. La sobrevida durante los 12 meses fue evaluada mediante el método de Kaplan (8).

\section{RESULTADOS}

\section{Población estudiada}

Fueron estudiados 47 pacientes, quienes se presentaron al Hospital San Juan de Dios de Santa Marta entre septiembre de 1980 y septiembre de 1985 . Todos tenían una bilirrubina total mayor de $3 \mathrm{mg} \%$. Fueron descartados 27 pacientes del estudio, debido a que el síndrome ictérico tenía algunos de lo siguientes diagnósticos: malaria (8), sepsis (7), carcinoma metastásico (2), hepatitis alcohólica (2), anemia de células falciforme (2), hepatitis de causa desconocida (2, no A no B ), fiebre tifoidea (1), absceso hepático (2). El resto de pacientes, 20, 12 hombres y 8 mujeres, llenaron los requisitos de hepatitis fulminante. De estos diez provenían de Santa Rosalía y diez de Julio Zawady. Siete de los casos (Casos No. 5, $6,7,13,14,16,17)$ procedían de tres núcleos familiares. (ver tabla 1). La edad de los pacientes oscilaba entre 5 a 54 años con una medida de 10.5. Ningún trabajador hospitalario estuvo comprometido con enfermedad hepática en un seguimiento de 12 meses, aunque no se les practicaron estudios serológicos.

\section{Manifestaciones clínicas}

De los 20 pacientes, 9 tenían antecedentes de hepatitis en el grupo familiar, doce de los veinte referían un episodio de ictericia y trece habían sido previamete vacunados contra fiebre amarilla. No existieron antecedentes previos de transfusiones, ni antecedentes de homosexualidad o drogadicción. De los veinte, a tres pacientes se les había practicado procedimientos odontológicos en los últimos dos meses (cuadro No.1)

La evolución fulminante de la hepatitis se caracterizó por hiperexcitabilidad, desorientación y manifestaciones de sistema nervioso central. De los 20 pacientes, 15 estuvieron en estado de coma y todos los que progresaron al coma murieron. Los signos más importantes fueron: ictericia (100\%), hepatomegalia (80\%), equimosis y petequias (75\%) y esplenomegalia palpable en 2 de los 20 (10\%). Hubo manifestaciones de coagulación intravascular diseminada, en 16 de los 20 casos ( $80 \%$ ), falla respiratoria en 15 , falla renal aguda en $9(45 \%$, y de los 20, 20\% tenían lesiones de piodermitis (cuadros No. 2, 3, 4 y 5).

\begin{tabular}{|c|c|c|}
\hline \multicolumn{3}{|c|}{$\begin{array}{c}\text { CUADRO NO. } 1 \\
\frac{\text { CARACTERISTICAS EPIDEMIOLOGICAS EN }}{\underline{20 \mathrm{CASOS}}}\end{array}$} \\
\hline CARACTERISTICAS & No. & $\%$ \\
\hline Residentes en Julio Zawady & 10 & 50 \\
\hline Residentes en Santa Rosalía & 10 & 50 \\
\hline Casos Familiares & 9 & 45 \\
\hline Historia previa de ictericia & 12 & 60 \\
\hline Contacto homosexual & 0 & 0 \\
\hline Uso de droga intravenosa & 0 & 0 \\
\hline Procedimiento dental reciente (6 meses) & 3 & 15 \\
\hline Edad 10.5 años & 10 & 50 \\
\hline Edad 10.5 años & 0 & 50 \\
\hline Masculinos & 12 & 60 \\
\hline Femenino & 8 & 40 \\
\hline
\end{tabular}

CUADRO NO. 2

MANIFESTACIONES CLINICAS $(\%)$

\begin{tabular}{lr}
\hline Ictericia & 100 \\
Estupor & 100 \\
Coma & 90 \\
Cambios en la personalidad & 90 \\
Debilidad y malestar & 90 \\
Letargo/somnolencia & 80 \\
Hiperexitabilidad & 70 \\
Agitación & 60 \\
Náusea y anorexia & 60 \\
Vómito & 60 \\
Constitpacion & 12 \\
Diarrea & 10 \\
Rash urticariforme & 10 \\
Cefalea & 10 \\
Materia fecal acolica & 10 \\
Prurito & 10 \\
Fiebre & 8 \\
&
\end{tabular}




\begin{tabular}{|lc|}
\hline \multicolumn{2}{|c|}{ CUADRO NO. 3} \\
HALLAZGOS FISICOS (\%) \\
\hline Ictericia & 100 \\
Encefalopatia-hepática & 100 \\
Hepatomegalia & 80 \\
Petequias y equimosis & 75 \\
Dolor en cuadrante superior derecho & 40 \\
Hipotensión ( sistólica $60 \mathrm{mmHg}$ ) & 20 \\
Taquicardia & 20 \\
Esplenomegalia & 10 \\
Estigmas de hipertensión portal & 10 \\
Angiomas aracnoideos & 10 \\
& \\
\hline
\end{tabular}

\begin{tabular}{|lc|}
\hline \multicolumn{2}{|c|}{$\begin{array}{c}\text { CUADRO NO. } 4 \\
\text { COMPLICACIONES (\%) }\end{array}$} \\
\\
\hline \\
Complicaciones en el sistema nervioso & 100 \\
Coagulacion intra vascular deseminada & 80 \\
Falla respiratoria & 75 \\
Coma & 75 \\
Falla renal aguda & 45 \\
Piodermitis & 20 \\
& \\
\hline
\end{tabular}

CUADRO NO. 5

HALLAZGOS DE LABORATORIO (\%)

\section{Elevación de la aminotrasferasa}

(8 $\mathrm{X}$ normal)

100

Hyperbilirubinemia

100

Prolongación de protrombina

100

Elevación de la fosfatasa alcalina

(2X normal)

50

Anemia severa ( $\mathrm{Hgb} 10 \%$ )

40

Hipoalbuminemia (3.5\%)

35

Trombocitopenia (<150.000/mm 3)

\section{Evolución clínica}

Ninguno de los pacientes se encontró desnutrido al ingreso. de los 20, 12 pacientes tuvieron complicaciones hemorrágicas; de estos 12,8 tenían hemorragias intracerebrales, 4 hemorragias digestivas, y 2 ambas. Hubo 14 defunciones en la fase aguda de la enfermedad menor o igual a 10 días (gráfico No.2 ). La causa de muerte de todos los casos fue una severa encefalopatía hepática. La supervivencia media estuvo entre 4 y 6 días. Todos los sobrevivientes fueron mayores de 10 años, 3 de estos pacientes murieron un mes después de la hospitalización. Unio de ellos falleció debido a complicaciones por cirrosis y una infección respiratoria aguda. Las causas específicas de muerte de los otros 2 pacientes que fallecieron en forma temprana (un mes o menos ), no fueron conocidas. Sólo 3 pacientes de sexo masculino sobrevivieron más de un mes. Un paciente tuvo el diagnóstico de hepatitis crónica activa y desapareció del seguimiento después de tres meses. Otro paciente falleció a causa de un hepatocarcinoma, tres meses después de salir del hospital. Sólo un paciente logró una recuperación completa después de un año de seguimiento (Tabla No. 1).

\section{Resultados de laboratorio}

En todos los pacientes se encontró que el tiempo de protrombina estaba prolongado y las transaminasas elevadas. Las fosfatasas alcalinas estuvieron aumentadas en 10 de los 20 pacientes. El nivel de hemoglobina estuvo entre 8 y 12 g. con una media de 10 . Dos pacientes que desarrollaron una hipoglicemia severa murieron rápidamente. Los niveles de albúmina estuvieron entre 3.7 y 2.5 g./100.

Todos los casos estudiados, 20 en total, estaban positivos para el HBs $\mathrm{Ag}$, negativos para anti HBs Ag con inmunoglobulina $\mathrm{M}, \mathrm{y}$ al mismo tiempo, positivos para anti Delta.

\section{Resultados histopatológicos}

De los 20 pacientes fallecidos, 18 mostraron en la autopsia una necrosis severa del hígado (Fig. 2). Uno de los casos tenía una fibrosis portal y reacción inflmatoria moderada, sin necrosis. En otro de los casos, el parénquima hepático estaba atravesado por tejido conectivo (Tabla 1). 


\begin{tabular}{|c|c|c|c|c|c|}
\hline \multicolumn{6}{|c|}{ TABLA No. 1} \\
\hline \multicolumn{6}{|c|}{ IDENTIFICACION DE CASOS, EVOLUCION CLINICA Y PATOLOGIA } \\
\hline CASO & EDAD & SEXO & RESISTENCIA & EVOLUCION & PATOLOGIA \\
\hline 1 & 5 & M & S. Rosa & Murió al 20 día & $\begin{array}{l}\text { ReacciónNecroinflamatoria } \\
\text { connecrosis } \\
\text { del hígado(NIRLN) }\end{array}$ \\
\hline 2 & 16 & $\mathrm{~F}$ & J. Zawady & Murió a los 30 días & NIR-NR \\
\hline 3\# & 20 & M & J. Zawady & Hepatitis Activa cronica & NIRNR \\
\hline 4 & 4 & M & S. Rosa & Murió el primer día & NIR-NR \\
\hline $5^{\star}$ & 11 & M & J. Sawady & Murió el 4o, día & NIR-NR \\
\hline $6^{*}$ & 8 & M & J. Sawady & Murió el 100 día & NIP-NA \\
\hline $7^{\star}$ & 13 & M & J. Sawady & Murió a los 30 días & NIP-NR \\
\hline 8 & 9 & M & S. Rosa & Murio al 40. dia & NIP-NR \\
\hline 9 & 26 & $\mathrm{~F}$ & S. Rosa & Murió al 80 día & Fibrosis Portal +NIR-LN \\
\hline 10 & 10 & $F$ & S. Rosa & Murió el primer día & NIR-NR \\
\hline 11 & 13 & M & S. Rosa & $\begin{array}{l}\text { No enfermedad } \\
\text { hepática en } 1 \text { año }\end{array}$ & NIR-NR \\
\hline 12 & 7 & $\mathrm{~F}$ & S. Rosa & Murió el 40 . día & NIR-NR \\
\hline $13^{*}$ & 7 & M & S. Rosa & Murió el 6o. dia & NIR-NR \\
\hline $14^{*}$ & 3 & M & S. Rosa & Murió el 4o. día & NIR-NR \\
\hline 15 & 6 & $\mathrm{~F}$ & J. Zawady & Murió el 4o. día & NIR-NR \\
\hline 16 & 12 & M & J. Zawady & Murió el 6o. día & NIR-NR \\
\hline $17^{\star}$ & 15 & M & J. Zawady & Murió el 7o. dia & NIR-NR \\
\hline $18^{*}$ & 8 & M & J. Zawady & Murió el 6o. día & NIR-NR \\
\hline 19 & 23 & $\mathrm{~F}$ & S. Rosa & Murió a los 30 días & NIR-NR \\
\hline 20 & 54 & M & J. Zawady & $\begin{array}{l}\text { Carcinoma hepático, } \\
\text { murió al tercer mes. }\end{array}$ & $\begin{array}{l}\text { Fibrosis portal con tejido } \\
\text { septal conjuntivo. }\end{array}$ \\
\hline $\begin{array}{l}\text { Todos I } \\
\text { *Casos } \\
\text { \# Se pe }\end{array}$ & $\begin{array}{l}\text { cientes } \\
\text { liares 5- } \\
\text { on desp }\end{array}$ & $\begin{array}{l}\text { on positi } \\
13-14 \text { y } \\
\text { de } 3 \text { mes }\end{array}$ & HBsAg y anti-De & tivos para anti-HBcAg & \\
\hline
\end{tabular}

El hallazgo histopatológico más prominente fue una esteatosis de los hepatocitos con infiltración linfocítica y eosinofílica con moderada colestasis (Figura 3). Dos casos fueron positivos para antígeno Delta por técnicas inmunoperoxidasa.

Cuatro pacientes que sobrevivieron al episodio agudo progresaron posteriormente a una falla hepática crónica, y en uno de ellos se confirmó en la necropsia un hepatocarcinoma.

\section{Tratamiento}

El protocolo de tratamiento requería de una restricción de proteínas y uso de neomicina con enemas evacuantes. En algunos casos se requirió del suministro de plasmas y otros derivados de la sangre.

En cuatro casos se suministró hidrocortisona por vía parenteral sin ninguna respuesta. 


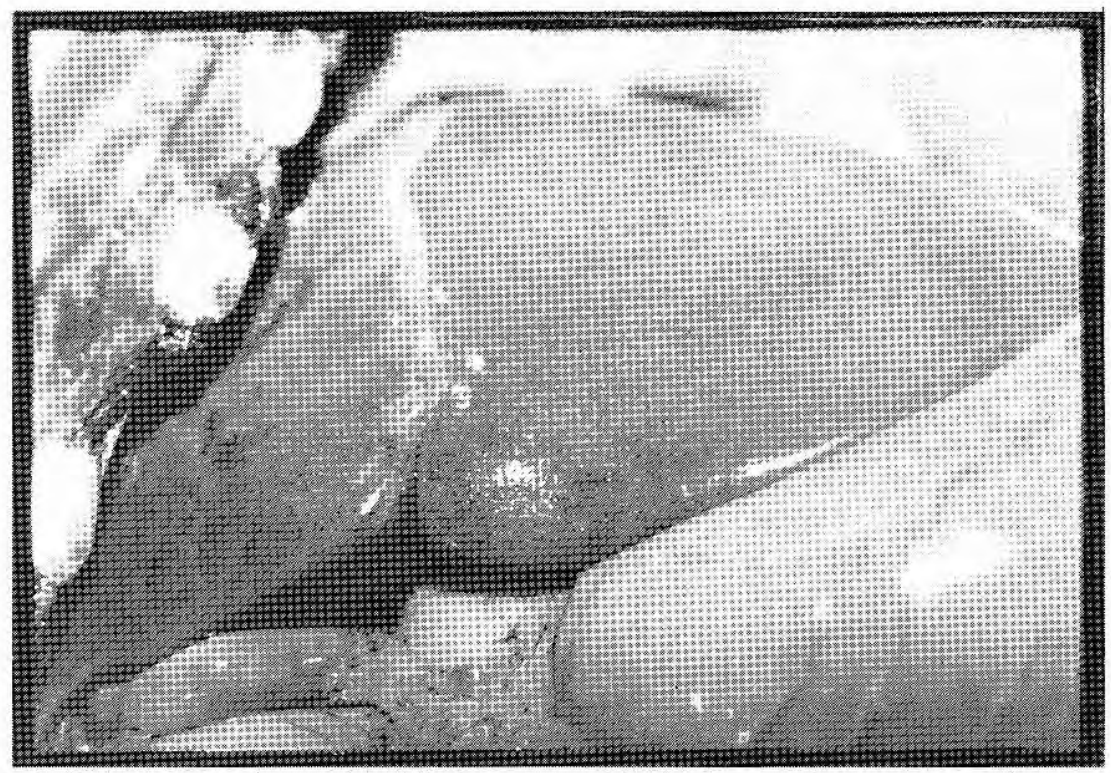

Fig. 2. HEPATITIS FULMINANTE. Macro: lesiones hemorrágicas.

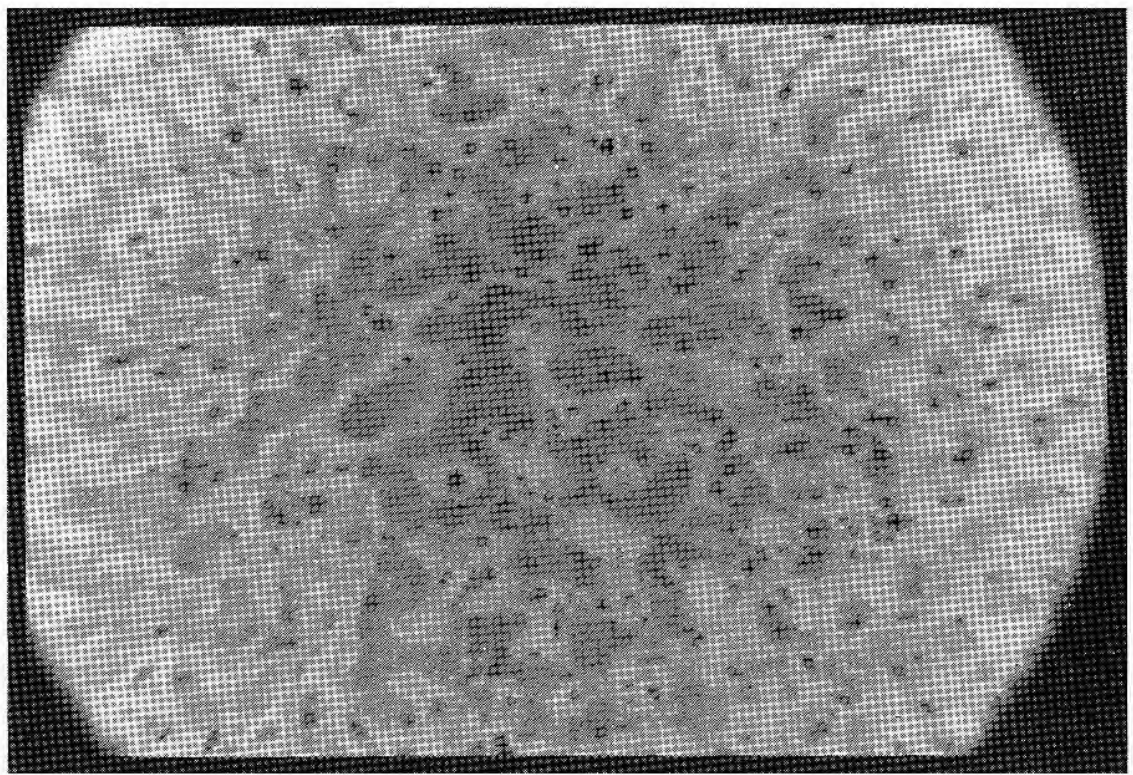

Fig. 3. HEPATITIS FULMINANTE. Micro: lesiones necroinflamatorias del hígado. 


\section{DISCUSION}

Desde 1935, Ramsey (4), describió algunos casos de hepatitis severa ocurridos en los trabajadores de la United Fruit Company, quienes laboraban en la zona bananera, una región cercana a la Sierra Nevada de Santa Marta. Durante más de 30 años, el doctor Gast Galvis, (10) del Instituto Nacional de Salud, realizó una importante colección histopatológica proveniente de viscerotomías y autopsias, en su mayoría de habitantes de los alrededores de la Sierra Nevada, encontrando formas severas de enfermedad inflamatoria del hígado. El estudio de estas muestras, ha sido continuado por Buitrago y colaboradores (6), quienes encontraron un alto porcentaje de positivididad del antígeno Delta. En el año de 1981, Aguilera y colaboradores (11), informaron de una alta prevalencia del virus de la hepatitis $B$, con estudios serológicos entre 13 y $37 \%$ positivos en julio Zawady y Santa Rosalía, la misma área en la cual nosotros encontramos entre un $30 \%$ y un $55 \%$, y donde además encontramos un $11 \%$ a un $22 \%$ de marcadores positivos para el virus Delta (gráfica No. 1). Con estos resultados y teniendo en cuenta la permanencia de los virus B y Delta, consideramos esta área como endémica para estos agentes.

En Colombia los estudios epidemiológicos de prevalencia de la hepatitis son inexactos y muchos casos no son reconocidos por ser formas sub-clínicas, mientras que en otros no se cumple con el obligatorio informe de las entidades de salud. En 1983, cuatrocientos ochenta casos de hepatitis fueron informados en el departamento del Magdalena (Servisalud-Magdalena).

La hepatitis fulminante de la Sierra Nevada de Santa Marta, es una forma severa de compromiso agudo del hígado; las manifestaciones del sistema nervioso central, encefalopatía consecutiva a la falla hepática, se presenta principalmente con cambios de conducta, hiperexcitabilidad, disminución de la capacidad mental, además trastornos del sueño, asterixis, estupor y coma. La necrosis del hígado con pequeña a mediana esteatosis de los hepatocitos y la infiltración linfocítica y eosinofílica estuvieron asociadas con la aumentada actividad de las alanino-transferasas y una prolongación del tiempo de protrombina con complicaciones hemorrágicas. La falla hepática junto con la encefalopatía fueron los hallazgos clínicos más prominentes. La oliguria y la falla hepática aguda empeoraron el pronóstico de los pacientes, con una temprana y rápida mortalidad que en nuestro estudio alcanzó un $70 \%$. Las defunciones ocurrieron principalmente dentro de los primeros diez días de hopitalización ( gráfico No. 2)

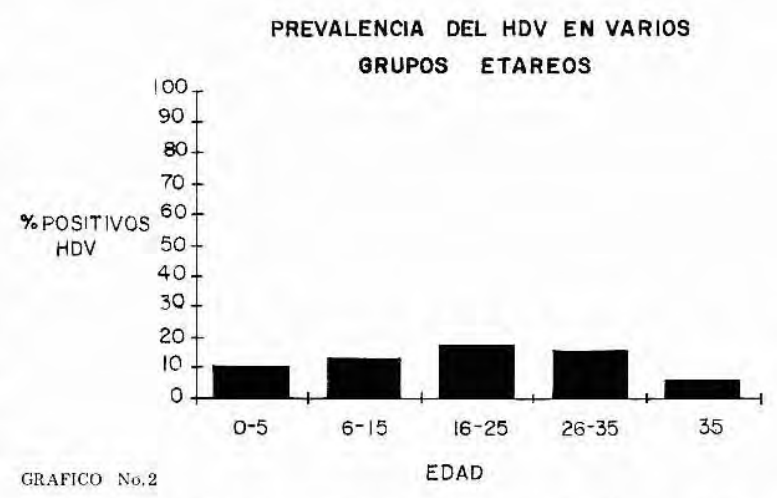

Las infecciones por el virus de la hepatitis B ocurren con mucha más frecuencia y en las edades inferiores de la vida en algunas áreas del mundo, como algunos países de Asia y Africa. Esto puede ser debido a las diferentes formas de transmisión en diferentes poblaciones (12). La edad temprana en la cual aparece, pudiera tener algunos factores de susceptibilidad en este grupo de individuos afectados (13). La infección persistente o estado de portador se presenta frecuentemente en forma neonatal de la hepatitis B (14). Un número de factores diversos se han encontrado que influyen en la persistencia de esta infección tales como edad, sexo, raza, estado inmunológico, estos tendrían que ver principalmente con la forma de evolución (14).

Aunque la forma aguda de infección con el virus Delta, es la más fácilmente reconocida, es posible que esta no sea la más frecuente. el virus Delta puede jugar también un papel importante en las enfermedades crónicas, especialmente en áreas endémicas en donde, como Italia, se han encontrado hasta en un $32 \%$ de portadores de HbsAg y compromiso de cirrosis en un $52 \%$, predominando estas formas en los pacientes con positividad para Delta (15). Informes recientes por Govidarajan y colaboradores (16) en California, mostraron que la proporción de pacientes con hepatitis crónica 
por virus B, tuvieron una mayor frecuencia de manifestaciones crónicas cuando se asociaba con el virus Delta. En la hepatitis de la Sierra Nevada, encontramos en las formas fulminantes una alta asociación entre estos dos virus (100\%). De los cinco casos que sobrevivieron, dos evolucionaron a una hepatitis crónica y uno a la cirrosis. Otro de los casos evolucionó hacia hepatocarcinoma, una entidad definitivamente asociada a la hepatitis B (17). Ningún estudio ha mostrado hasta el momento que la presencia del virus Delta aumente el riesgo de la aparición del hepatocarcinoma.

La superinfección de la hepatitis B con el virus Delta ha mostrado ser responsable de formas fulminantes (2).

El virus de la hepatitis Delta es un virus defectuoso que puede replicarse solamente en la presencia del virus de la hepatitis B (18). El aumento de la morbimortalidad producido por la asociación de B y Delta pudiera resultar de un daño complementario inducido por los dos agentes (19). Estudios en chimpancés mostraron dos distintos, pero posibles mecanismos sinergísticos de patogenicidad (20):

1. Daño por el virus de la hepatitis B, el cual está en relación con la respuesta inmune del huésped $y$,

2. Daño por Delta producido por una acción directa citopática en la células del hígado.

El agente Delta se ha demostrado en otros lugares como forma de superinfección asociado con el virus de la hepatitis B. Un estudio multicéntrico en Europa, por Smedile y colaboradores (2), mostró que el $39 \%$ de los pacientes con hepatitis fulminante por el virus $\mathrm{B}$, tenían anticuerpos para Delta. Una superinfección de la hepatitis Delta apareció en forma epidémica en Worcester, Massachusetts (21). Más de la mitad de los 50 casos tenían marcadores positivos para Delta y hubo 6 defunciones entre los 50 casos (12\%). En el área de los Angeles, una infección por hepatitis Delta, produjo un gran número de muertes por hepatitis fulminante en drogadictos y homosexuales (22).

Existen algunas características especiales en los casos de hepatitis Delta de la Sierra
Nevada. La edad media de los casos era de 10.5 años, comprometiendo un alto número de la población joven, en quienes la evolución de la enfermedad mostró una alta mortalidad (gráfico No. 3). La observación de la presencia simultánea de la enfermedad aguda en varios miembros de tres familias, sugiere su aparición en núcleos familiares o por áreas geográficas, con alguna predisposición especial (23). Una predisposición genética en la persistencia de la infección ha sido propuesta en relación con un gen autosómico recesivo. $(24,25)$.

La aparición del virus Delta, en poblaciones con alta prevalencia del virus de la hepatitis B, ha sido informado en dos presentaciones:

1. Infecciones endémicas y epidémicas las cuales no están asociada con la transmisión parenteral, en Italia y Sur América.

2. La forma esporádica de predominio y transmisión parenteral, en el resto de las poblaciones estudiadas (26).

Esta forma junvenil de hepatitis, en poblaciones heterosexuales, sin demostración de abuso a las drogas, presentes en el área de la Sierra Nevada es similar a los casos descritos por Hadler y colaboradores en los indios Yucpa en Venezuela (27). Ambas poblaciones habitan en condiciones sanitarias precarias con bajo nivel socio-económico y un alto índice de hacinamiento, con la utilización compartida frecuente entre ellos de materiales de uso personal.

Los virus de la hepatitis B y Delta no están presentes en las heces en una concentración apreciable y no hay evidencia de transmisión oralfecal como existe en la hepatitis A $(3,13)$. Sólo el suero (28), la saliva y el semen (29) han mostrado contener el virus de la hepatitis B, lográndose la transmisión parenteral a través de ellos. La transmisión del virus de madres de los recién nacidos se ha estimado que puede ocurrir en cerca de un $40 \%$ de los portadores en Taiwan (30). El transporte del virus de la hepatitis $B$ puede producirse en forma mecánica por mosquitos y por insectos (31) perono hay una demostración de que estos puedan servir como vectores importantes de transmisión. 


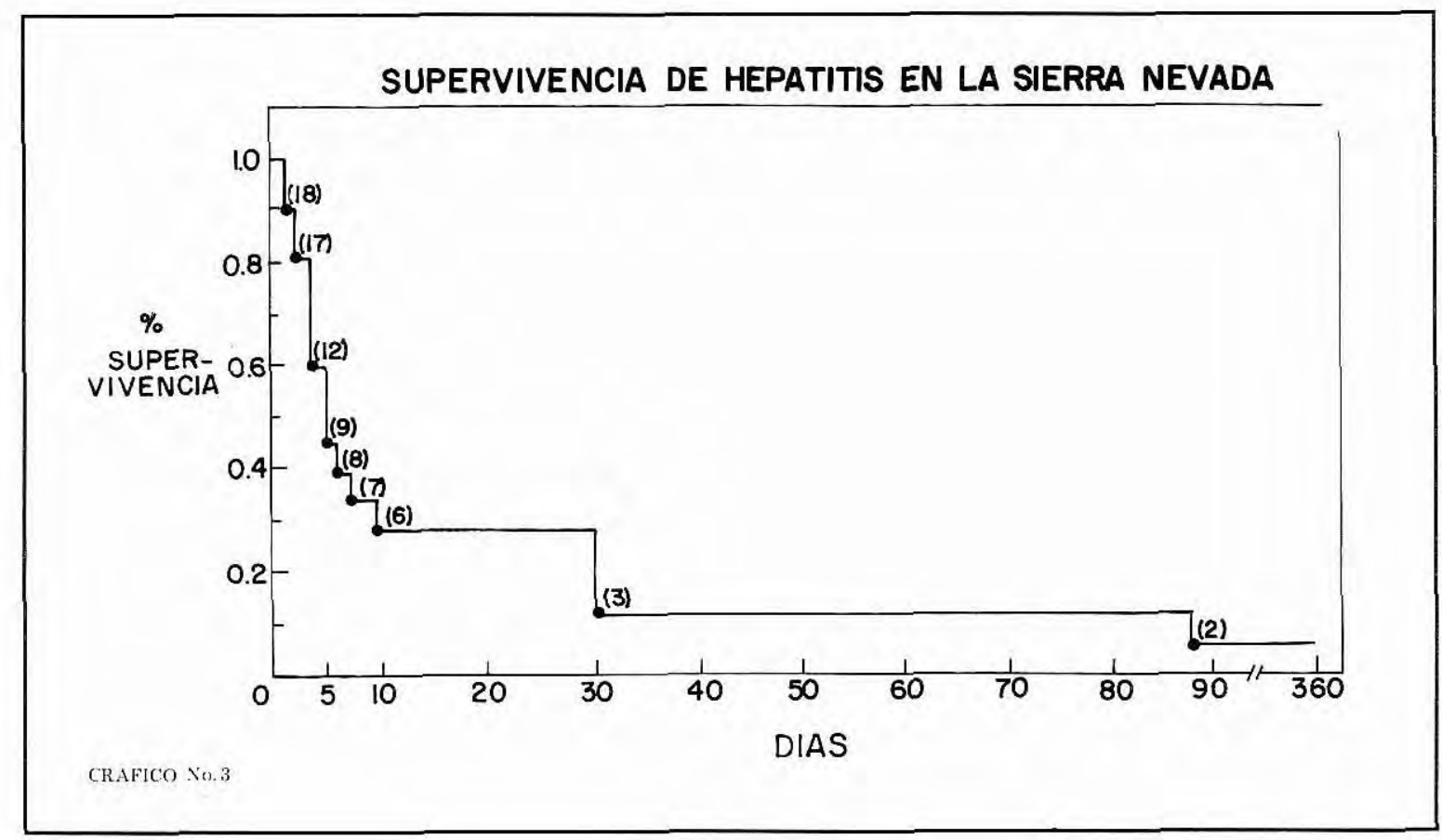

Basados en nuestros datos de los estudios de hepatitis en el Norte de Colombia, consideramos que la infección por B y Delta en estas zonas, no está principalmente ligada a la transmisión intravenosa sino que posiblemente está en relación con la aparición de soluciones de continuidad (heridas, piodermitis o erosiones en mucosas).

El tratamiento de la infección por Delta en el momento incluye sólo medidas de soporte para los pacientes. El uso de los corticoides no tiene ninguna importancia en el curso de la enfermedad. Debido a que la infección por Delta no puede ocurrir sin la simultánea infección con el virus de la hepatis $B$, se hace lógico pensar que la mejor medida profiláctica de disminución de casos es la utilización de la vacuna para la hepatitis B (32).

La hepatitis fulminante de la Sierra Nevada de Santa Marta es el resultado de la superinfección del virus Delta sobre portadores del virus de la hepatitis B, aunque la forma exacta de transmisión no se conoce. Este estudio sugiere que existe una relación epidemiológica importante en esta área geográfica y sus núcleos familiares. Por tratarse de una población perfectamente localizable, se presenta en esta área una gran oportunidad de poder utilizar la vacunación del a hepatitis B como arma importante en la erradicación de formas fulminantes crónicas.

\section{SUMMARY}

The paper presented hereby is an seroepidemiological study realized between September 1980 and October 1983; the study was carried out in a geographical region located in north Colombia South America. 258 persons were studied; Hepatitis A was found in 77 (93\%). HBsAg or anti-HBs were detected in 30.5 to $55 \%$ among the inhabitants of two small towns (Santa Rosalia and Julio Sawady) in a third village (Aracataca) the frecuency was $2.5 \%$, and $48.5 \%$ in the city of Santa Marta (population 250.000) evidence of exposure to Delta virus was confirmed in Julio Zawady and Santa Rosalia, $13.7 \%$ and $22 \%$ repectively, while in Aracataca Delta virus infection was negative. In 22 patientes fulminat Hepatitis was proved with serological evidence of hepatitis B infection, the mortabily was very high (65\%) the results suggest that the fulminat Hepatitis in this region could be the result of coinfection of Delta and B virus. 


\section{BIBLIOGRAFIA}

1. Rizzetto M.,Shih JW, Gerin JL: The hepatitis B virus associated to Delta antigen:isolation from liver, development of solidphase radioimmunoassays for Delta antigen and anti-Delta and partial characterization of Delta antigen. J Immunol. 1980; 125:138.

2. Smedile A,Farci P, Verme $\mathbf{G}$ et al. Influence of delta infection to severity of hepatitis B. Lancet 1982; 2: 947.

3. Rizzetto M, Purcell RH, Gerin JL. Epidemiology of HBVassociated Delta agent: Geographical distribution of anti-Delta and prevalence in politransfused HBsAg carries. Lancet 1890; 1: 1215.

4. Ramsey GH. Fever with jaundice in the province of Santa Marta. Preliminary report. Presented to the Colombian division of the United Fruit Company 1930.

5. Labbe A. The people, culture, and ceramic Art of Prehispanic Colombia. New York: An american foundation book. 1986.

6. Buitrago B, Popper Hans, Hadler Stephenc, et al. Specific Histologic Features of Santa Marta Hepatitis: A severe Form of Hepatitis Delta Virus infection in Northern South America. Hepatol, 1986; 6: 1285.

7. RizzettoM,Canese JWA, Arico S. et al. Imunofluorescense detection of new antigen-antibody system (delta-antidelta) associated with hepatitis B virus in Liver and serum of HBsAg carriers. Gut 1977; 18: 997.

8. Kaplan EL, Meier P. Nonparametric estimation from incomplete observationes. JAMA 1956; 53: 457.

9. Trey C, DavidsonzCS. The management of Fulminant hepatic failure, in Popper H, Schanffner Feds (1970): Progress in Liver Disease. New York, Grune and Stratton 1970; 3: 282.

10. Gast-Galvis A.Viscerotomia en Colombia. Resultado del examen histopatológico de 22.000 muestras de hígado humano. Revista Medica (Bogotá) 1945; 47: 283

11. Aguilera A,Morales A,Buitrago B, et al.Hepatitis Fulminante epidémica de la Sierra Nevada de Santa Marta. Biomédica 1981; 1: 187.

12. Zsmuness W, Harley EJ, Ikram H, et al. Socigdemographic aspects of the Epidemiology of Hepatitis B, in Vyas GN, Cohen SN, Schmid R (eds) Viral hepatitis. Philadelphia, Franklin Institute Press. 297.

13. Hoofnagle JH, Seef LB, Bales ZB, et al. Serologic responses in hepatitis B, In Vyas G, Cohen SN Schmid R (eds): Viral Hepatitis: A Contemporary Assesment ofEtiology, epidemiology, Pathogenesis and Prevention. Philadelphia, Franklin Institute Press 1978, 219.
14. Hoofnagle JH. Hepatitis. In Mandell G, Douglas R, and Bennett J. Principales and Practice of Infection Disease. Second ed. New York: John Wile and Sons 1002.

15. Columbo H, Cambieri R, Rumi M, et al. Long-Term delta superinfectation in hepatitis B surface antigen carriers and its relationship to the course of chronic hepatitis Gastroenterology. 1983; 85: 235.

16. Govindarajan S, De Cock K, and Redeker A. Natural Course of Delta Superintection in Chronic hepatitis BVirus Infected Patients: Histopathologic study with multiple Liver Biopsies. Hepatology. 1986; 6:4: 640 .

17. Beasley RP, Lin CC, Hwang Ly, Chien CS. Hepatocellular Carcinoma and hepatitis B virus: A prospective study of 22,707 men in Taiwan. Lancet 1981; 2: 1129.

18. Rizzetto M, Verme G, Recchia S. Chronic hepatitis in carriers of hepatitis B surface antigen, with intraheatic expression of delta antigen: An antive and progressing disease un responsive to immunosuppresive treatmen. Ann Internal Med 1983; 98 : 437.

19. Rizzetto M,Canese MG,Gerin JL,London et al. Transmision of hepatitis B virus associated delta antigen to Chimpanzees. J Infectss Dis. 1980; 141: 590.

20. Gerin JL, Ponzeto A, London WT, et al. Serial passage of the Delta agent in chimpazees. Federal Proceedings 1982;41:345.

21. De Cock K, Govindarajan S, Chin k, et al. Delta hepatitis in the los Angeles area: A report of 126 cases. Ann Intern Med 1986; 105: 108.

22. CDC: Delta hepatitis- Massachusetts. MMWR. 1984;33:493-494.

23. Rothman K. Clustering of Disease. Am Publi Health. Editorial. $77: 1$.

24. Blumberg BS, Friedlander JS, Woodside A, et al. Hepatitis and Australian antigen: Autosomol recessive inheritance of susceptibility to infection in humans. Procs Nat A cad Sci USA. 1969; 62: 1108

25. Hills WD, Hillis A, Bias WB, et al. Association of hepatitis B Surface antigenemia with locus specificities. N Engl J Med 1972; 196: 1310 .

26. Gust ID. The epidemiology of viral Hepatitis. In Vyas GN, Dienstag JL, Hoofnagle JH: Viral hepatitis and Liver Disease. Orlando, Florida: Grune and Stratton: 1984; 415.

27. Hadler SC, de Monson M, Ponzzetto A, et al. Delta virus infection and severe hepatitis: An epidemic in the Yucpa indians of Venezuela. Ann Intern Med: 1984; 100: 339. 
28A. VILLANUEVA, P. FRASER, R. GARCIA, P. OSPINO, P. ARIZA, T. BRIEN.

28. Barker LF, Murray R. Relationship of virus dose, of incubation time of clinical hepatitis and time of appearance of hepatitis associated antigen. Am J Med Sc: 1972; 163: 27.

29. Alter JH,Purcell RH, Gerin JL Transmission of hepatitis B to chimpanzees by hepatitis B surface antigen positive saliva and semen. Infect Immunol: 1977; 16: 928.

30. Okada K, Kainiyama I, Inometa M, et al. E antigen and anti$\mathrm{e}$ in the serum of asumptomatic carrier mothers as indicators of positive and negative transmission of hepatitis $b$ virus in their infants. N Engl J Med: 1976; 294: 746.

31 Prince AM, Metselaar D, Kapuko GW. Hepatitis B antigen in wild caught mosquitoes in Africa. Lancet 1972; 2: 247.

32. Szumuness W, Stevens CE, Harley EJ et al. Hepatitis B Vaccine. Demonstration of efficacy on a controlled clinical trial in a hig risk popularion in the United States. N Engl J Med:1980; $303 ; 833$. 